\title{
Effectiveness of experiential teaching method on the development of nursing students' skill competence: a systematic review and meta-analysis
}

Original article Bo Zhang ${ }^{\mathrm{a}, \mathrm{b}}$, Qing-Yong Ma ${ }^{\mathrm{c}, *}$, Xiang-Shu Cuib,*, Qi-Gui Xiaoc ${ }^{\mathrm{b}}$, Hong-Yan Jin ${ }^{\mathrm{b}}$, Xue Chen ${ }^{\mathrm{b}}$, Yi-Yan Chen ${ }^{\mathrm{b}}$

a Department of Nursing, School of Medicine, Xi'an Jiaotong University, Xi'an, Shaanxi 710061, China

${ }^{b}$ Department of Nursing, Yanbian University, Yanji, Jilin 133000, China

'Department of Hepatobiliary Surgery, The First Affiliated Hospital, Xi'an Jiaotong University, Xi'an, Shaanxi 710061, China

Received: 2 April 2020; Accepted: 22 June 2020; Published: 20 December 2020

Abstract: Objective: Skill competence is essential for nursing students and experiential teaching method has become increasingly popular in China's nursing education. To systematically evaluate the effects of experiential teaching method on the development of nursing students' skill competence, and to provide evidence for nursing education.

Methods: The China National Knowledge Infrastructure, VIP, Wanfang Data, PubMed, and Web of Science databases were searched from their inception until November 28, 2019. We screened the studies according to inclusion and exclusion criteria, extracted the data, and assessed the quality. Then, a meta-analysis was conducted.

Results: Totally 15 studies were included, and 1,633 nursing students were analyzed by Review Manager5.3 and Stata15.1 software. The results show that the experiential teaching method can significantly improve nursing students' nursing skills such as training (SMD $=1.05,95 \% \mathrm{Cl}: 0.95-1.16, P=0.000)$, learning interest ( $\mathrm{ES}=0.93,95 \% \mathrm{Cl}: 0.79-1.06)$, ability to analyze and solve problems ( $\mathrm{ES}=0.75,95 \% \mathrm{Cl}: 0.55-0.94$ ), ability to judge and innovative thinking ( $\mathrm{ES}=1.01$, $95 \% \mathrm{Cl}: 0.77-1.25)$, abilities of understanding and perception $(\mathrm{ES}=0.59,95 \% \mathrm{Cl}: 0.34-0.83$ ), and teaching satisfaction (ES $=1.26,95 \% \mathrm{Cl}: 1.13-1.4)$.

Conclusions: The results suggest that the experiential teaching method is more effective for the nursing students' skill competence than traditional teaching in China. However, due to the heterogeneity and bias risk, a large sample and high-quality studies are needed in future to confirm its effectiveness.

Keywords: experiential teaching method $\bullet$ nursing education $\bullet$ meta-analysis $\bullet$ nursing students $\bullet$ skill competence $\bullet$ randomized controlled trial

(c) Shanxi Medical Periodical Press.

How to cite this article: Zhang B, Ma QY, Cui XS, et al. Effectiveness of experiential teaching method on the development of nursing students' skill competence: a systematic review and meta-analysis. Front Nurs. 2020;4:359-368. 


\section{Introduction}

Nowadays, the medical environment is becoming more and more complex and patients' health needs are increasing; therefore, it is more and more necessary for nurses to master good clinical skills. Clinical nursing skills are an important part of nursing education and nursing disciplines. ${ }^{1}$ In addition, nursing students may be required to assume professional responsibilities related to their role as nursing practitioners. ${ }^{2}$ This is challenging. However, traditional education is not sufficient to meet this requirement. ${ }^{3}$ Previous research has found that under the training of traditional teaching methods, the nursing students in our country have relatively solid theoretical knowledge, but their operational ability is low. ${ }^{4}$ Experiential learning is defined as the process of creating knowledge through transformative experiences outside the traditional teaching method, and it is widely used in nursing education. ${ }^{5,6}$ Experiential learning engages the learner by providing a more natural and intuitive learning environment. ${ }^{7,8}$ It can meet the needs of the times and it has been recognized and applied by the education community. In the field of nursing education, experiential teaching has been used in the fundamentals of nursing, surgical nursing, medical nursing, and other courses..$^{9,10}$ Experiential learning describes a continuous process whereby concrete experience leads to observation, reflection, and abstract conceptualization. ${ }^{11,12}$ Quantitative assessments can provide new ideas for implementing experiential teaching method and provide a basis for the intervention of nursing education in China.

\section{Methods}

\subsection{Search strategies}

This research systematically retrieved randomized controlled trials (RCTs) indexed by Chinese and foreign databases such as CNKI, VIP, Wanfang data, PubMed, and Web of Science, and the search time was from database establishment to November 28, 2019. The subject words were combined with keywords. English keywords included "experiential teaching method" or "experiential learning method" and "nursing student" or "nursing education." During the process of reviewing the literature, the search strategy should be adjusted at any time to collect the references attached to the literature.

\subsection{Inclusion criteria}

Inclusion criteria for the studies were: (1) describing a randomized controlled trial, (2) using nursing students, (3) using experiential learning method as an educational method in the intervention groups, and (4) the control group adapting the traditional teaching method.

Exclusion criteria were: (1) the nursing skill score was not evaluated, (2) the data was incomplete, (3) the full text was not available, and (4) the article was repeated.

\subsection{Data extraction}

We independently extracted information according to the inclusion and exclusion criteria. The differences were settled through discussion in order to reach a consensus. Data extraction is accomplished by filling in a form that contains the following data: author, year of publication, research object, sample size, course preparation time, and so on.

\subsection{Quality assessment}

We used the Cochrane risk assessment tool to independently assess the risk of potential bias in randomized controlled trials. Evaluation projects include random sequence generation, allocation of hiding, blindness of participants and personnel, blindness of outcome evaluation, incompleteness of result data, selection reports, and other possible causes of deviation. For all randomized controlled trials, each project is described as having a low risk of bias, a high risk of bias, or an uncertain risk of bias.

\subsection{Statistical analyses}

Review Manager5.3 and STATA 15.1 software were used to analyze the data. The dichotomous data were analyzed using the $\mathrm{ES}$ values and the $95 \% \mathrm{Cl}$ for the ES. $x^{2}$ test and the $l^{2}$ statistic were also used. If $p>0.1$ and $l^{2}<50 \%$, the homogeneity was considered and the fixed-effect model was selected for analysis. If $p<0.1$ and $l^{2}>50 \%$, random effect model was used. In addition, subgroup analysis was carried out according to the possible heterogeneity factors. We assessed publication bias using Egger's test.

\section{Results}

\subsection{Literature searches}

A total of 2,281 potential related studies were obtained from the literature search; 1,250 duplicated papers were removed, 105 papers were screened after reading articles and abstracts, and 90 papers were removed from the inclusion criteria by further reading. Finally, 15 studies $^{13-27}$ were included (Figure 1). 


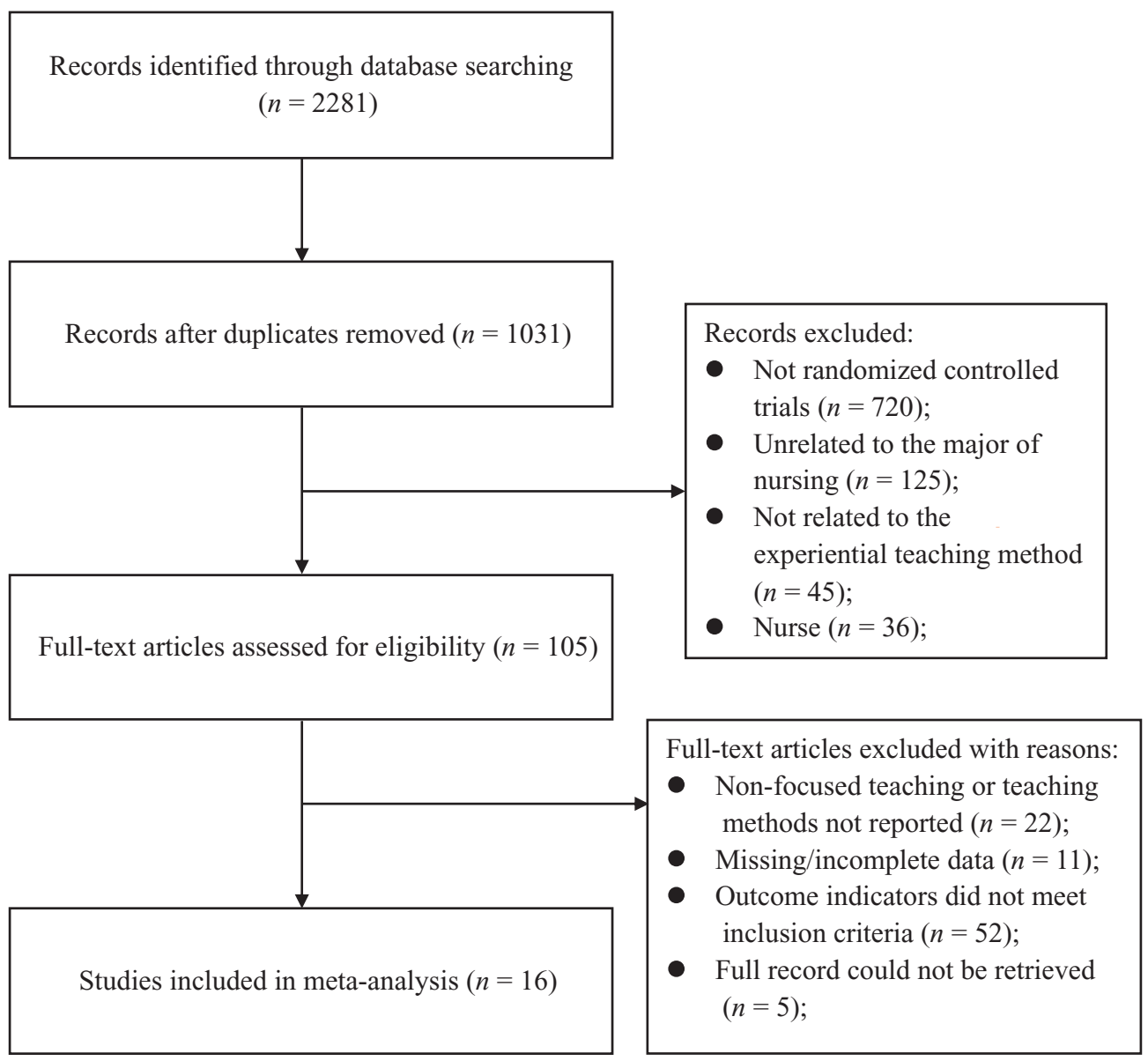

Figure 1. Flowchart of the literature search.

\subsection{Study characteristics}

Table 1 shows a summary of the research features. A total of 15 randomized controlled trials were conducted including 1,663 students. Among them, there were 818 students in the experimental group and 815 students in the control group. The 15 randomized controlled trials were published in Chinese journals from 2014 to 2019. The research population is diverse, including secondary vocational students, college students, and undergraduates. The sample size ranged from 30 to 156 participants. The duration of research interventions ranged from $<1$ month to $\geq$ months. All the results were measured by skill score. All studies covered the overall gender, age, education level, etc. of the intervention group and the control group, indicating that all baseline levels prior to intervention were consistent and comparable.

\subsection{Risk of bias in the included studies}

Randomization has been reported in all studies, but only six studies reported their methods for generating randomized sequences (Table 2). Of these six studies, four used randomized table, one used a lottery, and one used the block randomization. None of the studies described their allocation concealment. Only one study reported that the assessors were blinded. All studies reported complete outcome data. The results showed that the quality grade of the 15 included literatures was B. We did not find any selective reports or other biases in these 15 studies. In addition, all the studies showed that at the baseline level, there was no significant difference between experiential teaching method and traditional teaching method in terms of age, gender, and academic performance.

\subsection{Meta-analysis results}

All the studies used students' skill scores as outcome indicators. In the random effect model, we found that compared with traditional teaching methods, the experiential teaching method significantly improved the performance of nursing students (standardized mean difference $=1.05,95 \% \mathrm{Cl}: 0.95-1.16, P=0.000)$ (Figure 2). There is a high level of heterogeneity $\left(l^{2}=86.6 \%\right)$. 


\begin{tabular}{|c|c|c|c|c|c|c|c|c|c|}
\hline Included study & Design & $T(N)$ & $\mathrm{C}(\mathrm{N})$ & Gender & Educational background & $\begin{array}{l}\text { Duration of } \\
\text { intervention }\end{array}$ & Subject & Area & Outcomes \\
\hline Mao et al. ${ }^{18}(2016)$ & $\mathrm{RCT}$ & 40 & 40 & Female & $\begin{array}{l}\text { Secondary vocational } \\
\text { school education }\end{array}$ & No report & Fundamentals of nursing & South & (1)(2) \\
\hline Shen and Zhu'9 (2018) & $\mathrm{RCT}$ & 50 & 50 & Mixed & $\begin{array}{l}\text { Secondary vocational } \\
\text { school education }\end{array}$ & No report & Fundamentals of nursing & South & (1)(2) \\
\hline Zhou²4 (2019) & RCT & 35 & 35 & No report & $\begin{array}{l}\text { Secondary vocational } \\
\text { school education }\end{array}$ & 17 months & Mixed nursing & South & (1)(2) \\
\hline Li et al. ${ }^{15}$ (2015) & RCT & 54 & 52 & No report & Junior college & No report & Fundamentals of nursing & South & (1)(3) \\
\hline Zhou and Shi' ${ }^{25}$ (2019) & RCT & 52 & 55 & Female & Junior college & No report & Surgical nursing & South & (1)(3)(6) \\
\hline Chen $^{13}(2015)$ & RCT & 30 & 30 & Mixed & Undergraduate & 11 months & Emergency nursing & South & (1)(4) \\
\hline$Y_{i i^{21}}(2016)$ & RCT & 54 & 52 & No report & Junior college & 8 months & Mixed nursing & South & (1)(2) \\
\hline $\operatorname{Tian}^{20}(2017)$ & RCT & 56 & 55 & No report & Junior college & 4 months & Medical nursing & North & (1)(2)(3)(4) \\
\hline $\mathrm{Yi}^{22}$ (2016) & RCT & 80 & 80 & Mixed & Junior college & No report & Nursing Aesthetics & North & (1)(2) \\
\hline $\mathrm{Li}^{16}(2017)$ & RCT & 156 & 151 & Mixed & Junior college & 2 weeks & Fundamentals of nursing & North & (1)(2)(3) \\
\hline Zhang et al. ${ }^{27}$ (2016) & RCT & 42 & 42 & Female & Junior college & 4 weeks & Surgical nursing & South & $(1)(2)(3)(4)$ \\
\hline $\mathrm{Du}^{14}(2015)$ & RCT & 45 & 45 & Mixed & Junior college & 6 weeks & Medical nursing & South & $(1)(3)(5)(6)$ \\
\hline Li and Zhang17 (2018) & RCT & 50 & 50 & No report & Undergraduate & 6 weeks & Medical nursing & South & (1)(4)(6) \\
\hline Yang and Zhang ${ }^{23}$ (2014) & RCT & 40 & 40 & Mixed & Undergraduate & 6 weeks & Surgical nursing & South & $(1)(3)(5)(6)$ \\
\hline Zhang ${ }^{26}$ (2018) & RCT & 50 & 50 & Mixed & Undergraduate & 6 weeks & Medical nursing & North & $(1)(3)(5)(6)$ \\
\hline
\end{tabular}

Note: (1) skill score; (2) teaching satisfaction; (3) learning interest; (4) ability to judge and innovative thinking; (5) ability to understand and perceive;

(6) ability to think and analyze problems.

Table 1. Characteristics of the 15 studies of the effect of the experiential teaching method on nursing students' education.

\begin{tabular}{|c|c|c|c|c|c|c|c|}
\hline \multirow[t]{2}{*}{ Included study } & \multirow{2}{*}{$\begin{array}{l}\text { Random sequence } \\
\text { generation }\end{array}$} & \multirow{2}{*}{$\begin{array}{l}\text { Allocation } \\
\text { concealment }\end{array}$} & \multicolumn{2}{|r|}{ Blinding } & \multirow{2}{*}{$\begin{array}{l}\text { Incomplete } \\
\text { outcome data }\end{array}$} & \multirow{2}{*}{$\begin{array}{l}\text { Selective } \\
\text { reporting }\end{array}$} & \multirow[t]{2}{*}{ Other bias } \\
\hline & & & Participants & Outcome assessment & & & \\
\hline Mao et al. ${ }^{18}$ (2016) & Yes (randomized table) & Unclear & Unclear & Unclear & None & None & None \\
\hline Shen and Zhu'9 (2018) & Yes (randomized table) & Unclear & Unclear & Unclear & None & None & None \\
\hline Zhou ${ }^{24}$ (2019) & Yes (randomized table) & Unclear & Unclear & Unclear & None & None & None \\
\hline Li et al. ${ }^{15}$ (2015) & Unclear & Unclear & Unclear & Unclear & None & None & None \\
\hline Zhou and Shi25 (2019) & Yes (lottery) & Unclear & Unclear & Unclear & None & None & None \\
\hline Chen $^{13}(2015)$ & Unclear & Unclear & Unclear & Unclear & None & None & None \\
\hline$Y_{i 21}(2016)$ & Unclear & Unclear & Unclear & Unclear & None & None & None \\
\hline $\operatorname{Tian}^{20}(2017)$ & Unclear & Unclear & Unclear & Unclear & None & None & None \\
\hline $\mathrm{Yi}^{22}$ (2016) & Unclear & Yes & Unclear & Unclear & None & None & None \\
\hline $\mathrm{Li}^{16}(2017)$ & Unclear & Unclear & Unclear & Unclear & None & None & None \\
\hline Zhang et al. ${ }^{27}$ (2016) & Unclear & Unclear & Unclear & Unclear & None & None & None \\
\hline $\mathrm{Du}^{14}(2015)$ & Unclear & Unclear & Unclear & Unclear & None & None & None \\
\hline Li and Zhang17 (2018) & Unclear & Unclear & Unclear & Unclear & None & None & None \\
\hline Yang and Zhang ${ }^{23}$ (2014) & Yes (randomized table) & Unclear & Unclear & Unclear & None & None & None \\
\hline Zhang ${ }^{26}$ (2018) & $\begin{array}{l}\text { Yes (block } \\
\text { randomization) }\end{array}$ & Unclear & Unclear & Unclear & None & None & None \\
\hline
\end{tabular}

Table 2. Risk of bias assessment of the 15 included studies.

\subsubsection{The results of the secondary outcome indicators}

The feedback of nursing students on the experiential teaching method showed that the experimental group improved in the learning interest $(E S=0.93,95 \% \mathrm{Cl}$ : 0.79-1.06), ability to analyze and solve problems
$(E S=0.75,95 \% \mathrm{Cl}: 0.55-0.94)$, ability to judge and innovative thinking (ES $=1.01,95 \% \mathrm{Cl}$ : $0.77-1.25)$, the abilities of understanding and perception ( $E S=0.59$, 95\% Cl: 0.34-0.83), and teaching satisfaction (ES $=1.26,95 \% \mathrm{Cl}: 1.13-1.40)$ (Table 3). 


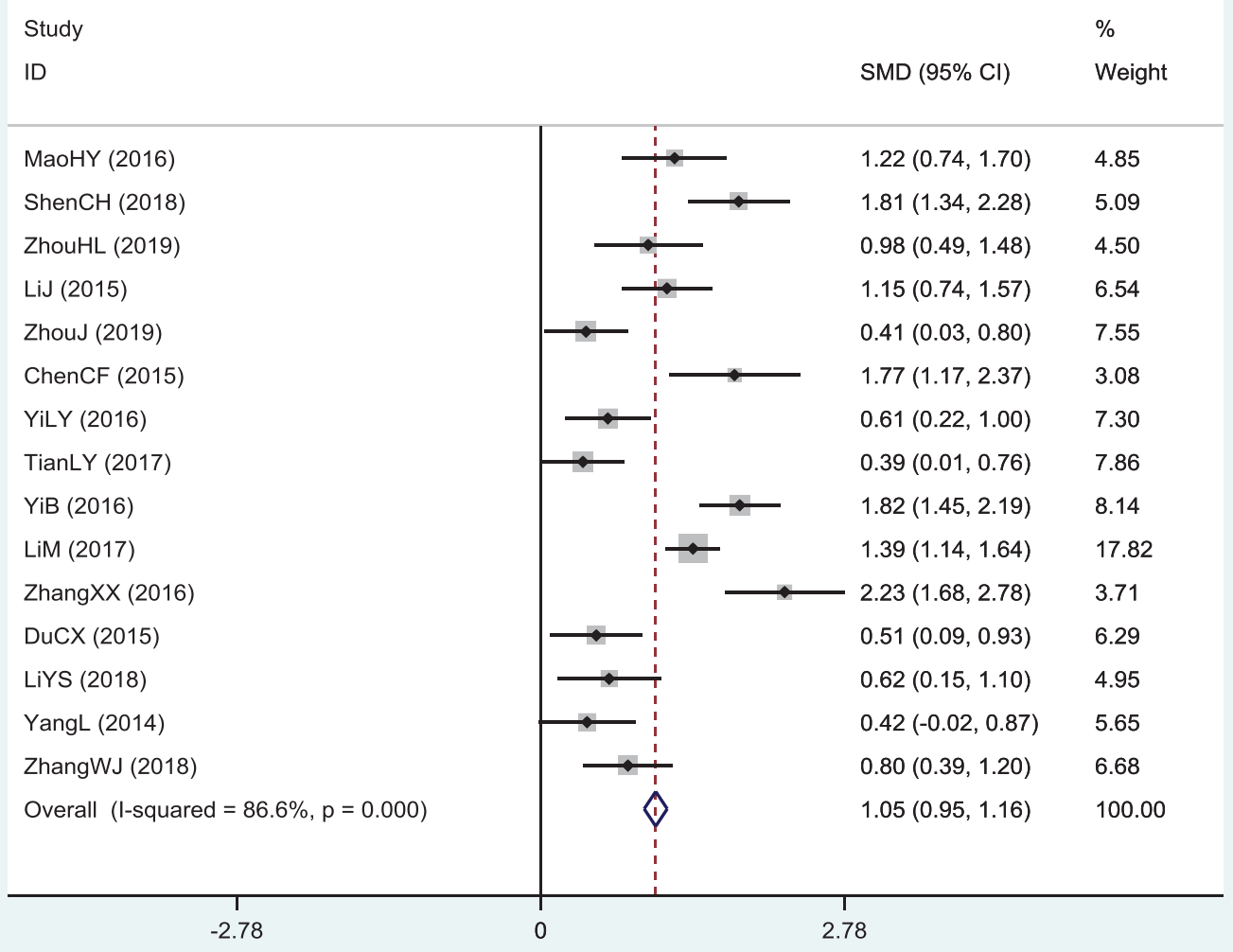

Figure 2. Forest plot of the nursing students' skill score.

\begin{tabular}{lcccc}
\hline Students' feedback & Number of included studies & ES (95\% Cl) & $P^{2}(\%)$ & $P$ (Egger's test) \\
\hline \hline Learning interest & 8 & $0.93(0.79-1.06)$ & 88.40 & 0.652 \\
Ability to judge and innovative thinking & 4 & $1.01(0.77-1.25)$ & 92.20 & 0.122 \\
Ability to understand and perceive & 3 & $0.59(0.34-0.83)$ & 0.00 & 0.306 \\
Ability to think and analyze problems & 5 & $0.75(0.55-0.94)$ & 88.40 & 0.079 \\
Teaching satisfaction & 8 & $1.26(1.13-1.40)$ & 88.30 & 0.813 \\
\hline
\end{tabular}

Table 3. The result of the secondary outcome indicator.

\subsubsection{Subgroup analyses}

To find the source of heterogeneity, a subgroup analysis was performed based on the strata of gender, educational background, duration of intervention, subject, and area. Using the random effects model, the results of the subgroup analysis are shown in Table 4 and Figure 3. It was found that when five studies were excluded, the overall results had a great impact. By reviewing the literature, it was found that gender, intervention time, educational background, region, and theme were different. The results of subgroup analysis showed that intervention time and subject could explain heterogeneous sources of nursing students' operational skill scores
(1-4 months, $P=0.63, I^{2}=0 \%$ ) and subject (internal medicine nursing, $P=0.53, I^{2}=0 \%$; basic nursing, $P=0.19, I^{2}=37 \%$ ) in a certain course (Figures 4 and 5). This study found that the effect of intervention time on improving nursing students' operation skills was more significant when the intervention time was 1-4 months, which was basically consistent with some research. This may be due to the intervention of experiential teaching method on operation skills needed for a process, the intervention time was too long to create fatigue, and the intervention time was too short for nursing students. This study also found that experiential teaching method is more effective in operation skills of medical nursing, 


\begin{tabular}{|c|c|c|c|c|c|c|}
\hline \multirow[t]{2}{*}{ Characteristics } & \multirow[t]{2}{*}{$n$} & \multirow[t]{2}{*}{ Pooled Cohen's d (95\% Cl) } & \multirow[t]{2}{*}{$P$} & \multicolumn{2}{|c|}{ Heterogeneity test } & \multirow[t]{2}{*}{$P$ (Egger's test) } \\
\hline & & & & $1^{2}$ & $P$ & \\
\hline Gender & & & & & 0 & \\
\hline Female & 3 & $1.08(0.81,1.34)$ & 0 & 0.931 & & 0.10 \\
\hline Mixed & 7 & $1.24(1.09,1.38)$ & 0 & 0.877 & & 0.44 \\
\hline No report & 5 & $0.72(0.54,0.91)$ & 0.06 & 0.546 & & 0.78 \\
\hline Educational background & & & & & 0 & \\
\hline Secondary vocational school education & 3 & $1.35(1.08,1.63)$ & 0.04 & 0.672 & & 0.57 \\
\hline Junior college & 8 & $1.06(0.93,1.19)$ & 0 & 0.908 & & 0.21 \\
\hline Undergraduate & 4 & $0.80(0.57,1.03)$ & 0 & 0.775 & & 0.84 \\
\hline Subject & & & & & 0 & \\
\hline Fundamentals of nursing & 4 & $1.38(1.20,1.56)$ & 0.18 & 0.380 & & 0.27 \\
\hline Surgical nursing & 3 & $0.82(0.56,1.07)$ & 0 & 0.939 & & 0.93 \\
\hline Medical nursing & 4 & $0.57(0.36,0.78)$ & 0.52 & 0 & & 0.23 \\
\hline Other & 4 & $1.27(1.05,1.49)$ & 0 & 0.871 & & - \\
\hline Duration of intervention & & & & & 0 & \\
\hline$\leq 1$ month & 2 & $1.54(1.31,1.76)$ & 0 & 0.866 & & 0.78 \\
\hline $1-4$ months & 5 & $0.54(0.35,0.73)$ & 0.63 & 0 & & 0.14 \\
\hline$>4$ months & 3 & $0.96(0.69,1.24)$ & 0 & 0.801 & & 0.69 \\
\hline No report & 5 & $1.26(1.08,1.45)$ & 0 & 0.879 & & 0.01 \\
\hline Area & & & & & 0 & \\
\hline South & 11 & $0.96(0.82,1.10)$ & 0 & 0.847 & & 0.43 \\
\hline North & 4 & $1.18(1.02,1.35)$ & 0 & 0.914 & & 0.57 \\
\hline
\end{tabular}

Table 4. Subgroup analyses.

which is basically consistent with some research. ${ }^{24}$ This study also found that experiential teaching method is more effective in operating skills of medical nursing, which is basically consistent with the finding of some researches. It may be due to the higher requirements for the operation skills of nursing students in clinical work. Implementing experiential teaching method can better integrate nursing students into the situation and achieve this goal; theory and practice are closely integrated. ${ }^{25}$

\subsubsection{Sensitivity analysis}

We also conducted a sensitivity analysis. This study used different models to analyze the combined effects. There was no significant change noted when comparing the results of the two models, suggesting that the results of this study have good robustness (Table 5).

\section{Discussion}

\subsection{Summary of the main findings}

Previous papers have a few samples and lack students' feedback, and, therefore, there is not enough data to test the impact of experiential teaching methods. The meta-analysis of 15 studies is the first systematic report summarizing the impact of experiential teaching on the skills score and other aspects of Chinese nursing students. Studies have shown that experiential teaching methods significantly improve the skill level of these students. In addition, compared to the traditional teaching methods, experiential teaching methods are more effective in improving learning interest and the ability to analyze and solve problems.

Experiential teaching methods are superior to traditional teaching methods. The reason are as follows. First, experiential teaching methods are studentcentered; it makes students responsible for their own learning. It allows students to depart from intellectual discussion and didactic learning to delve into more personal experience. ${ }^{28,29}$ Second, experiential teaching method can promote nursing students to transfer knowledge and skills through experiencing-observing and reflecting-forming the model of theory-applying to practice, so as to improve the operational skills, the ability to analyze and solve problems, interest and initiative in learning, and so on. ${ }^{30-33}$ Third, experiential teaching method can be used as a clinical learning 


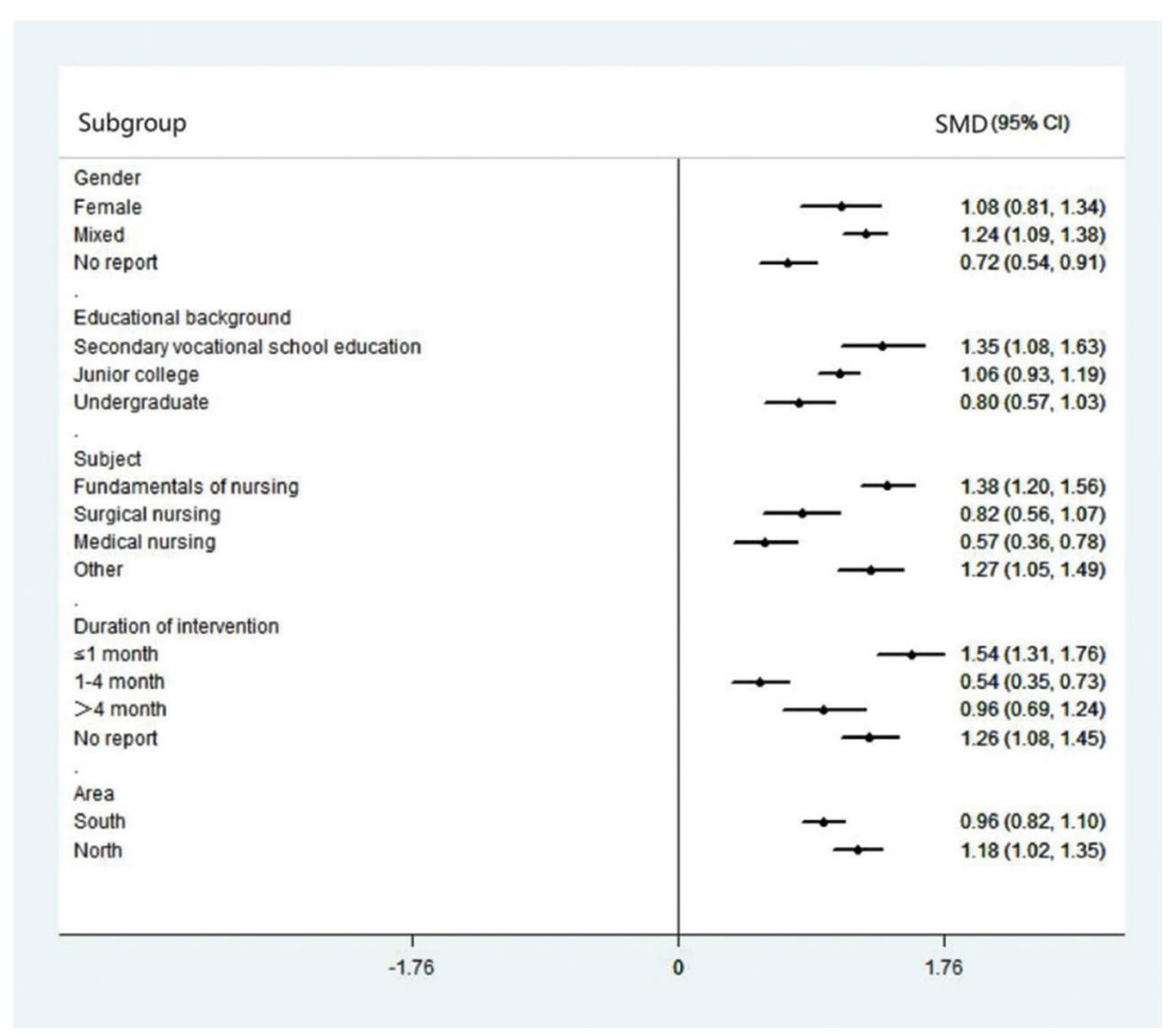

Figure 3. Summary of subgroup analyses for the skills score.

environment to deepen nursing students' understanding of professional roles. These students' exposure to experiential teaching strategy contributed to their clinical reasoning and critical thinking development in comparison to the students taught in a traditional environment. ${ }^{30}$ Fourth, through the application of experiential teaching method, students can interact with learning materials more effectively and independently. As a result, it increases cooperation with students in the classroom and interaction between teachers and students.

\subsection{Limitations of this study}

(1) Both the overall analysis and the subgroup analysis have significant heterogeneity, which reduces the reliability of meta-analysis estimates. (2) Some of the restrictions are related to publishing bias, which may be because positive results are easier to publish.

\subsection{Implications for future research}

The implementation of the experiential teaching method is basically in its initial stages in China, and this model should be promoted in future nursing education. In order to understand the experiential teaching method more objectively and fully, it is necessary to promote further application of the experiential teaching method in China. Future research also needs to take into account other factors that influence the effect of experiential teaching, such as the workload of the students and the role of the teacher in the experiential teaching method.

\section{Conclusions}

Skilled and exquisite nursing operation skills are an important manifestation of the combination of theory and practice. They not only help patients recover, but also improve their abilities. Nowadays, the demand for highquality nursing talents is increasing. How to improve nursing operation skills of nursing students is an important issue for nursing educators and clinical nursing workers. 


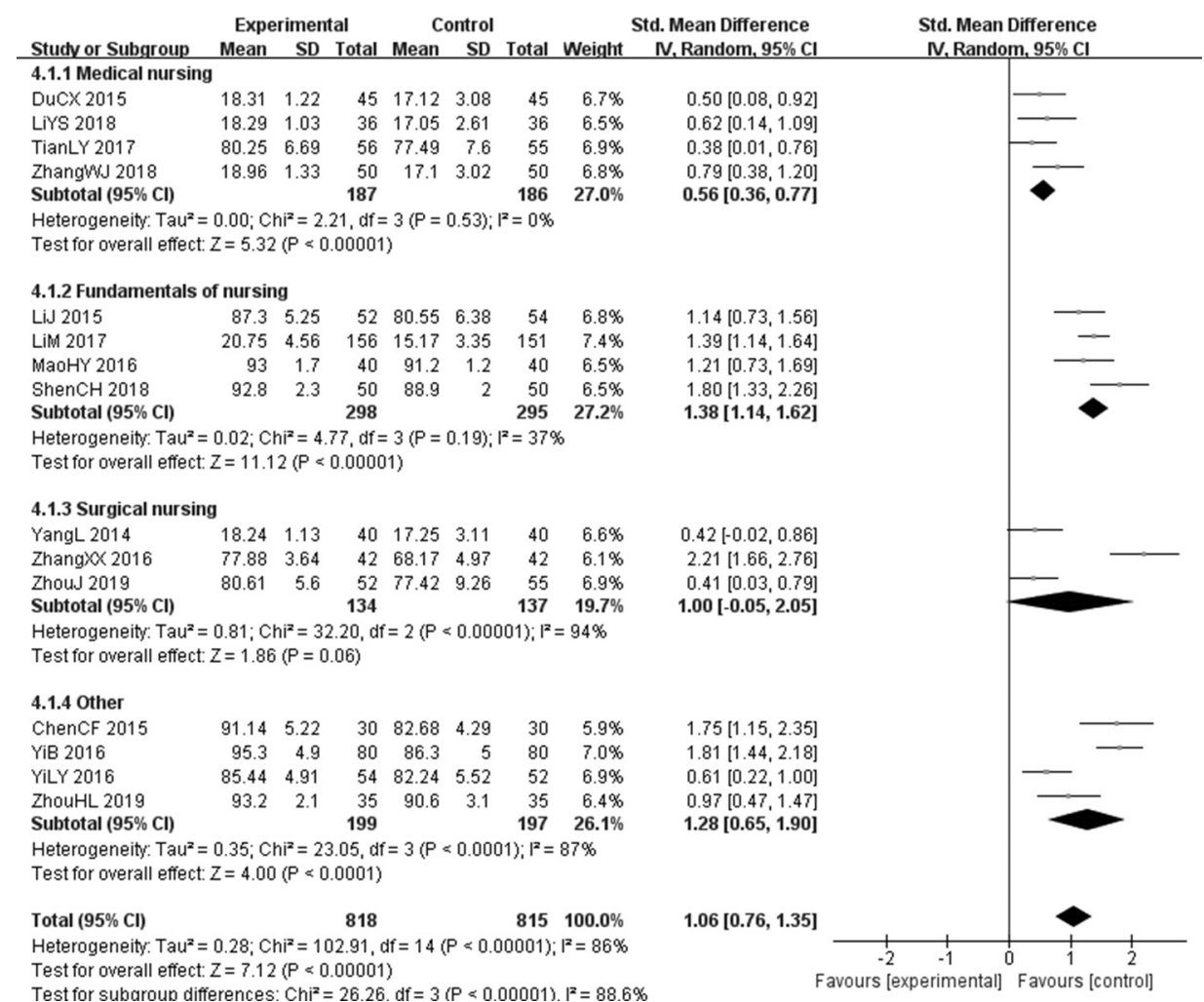

Figure 4. Subgroup analysis of the effect of subjects on nursing students' operational achievements.

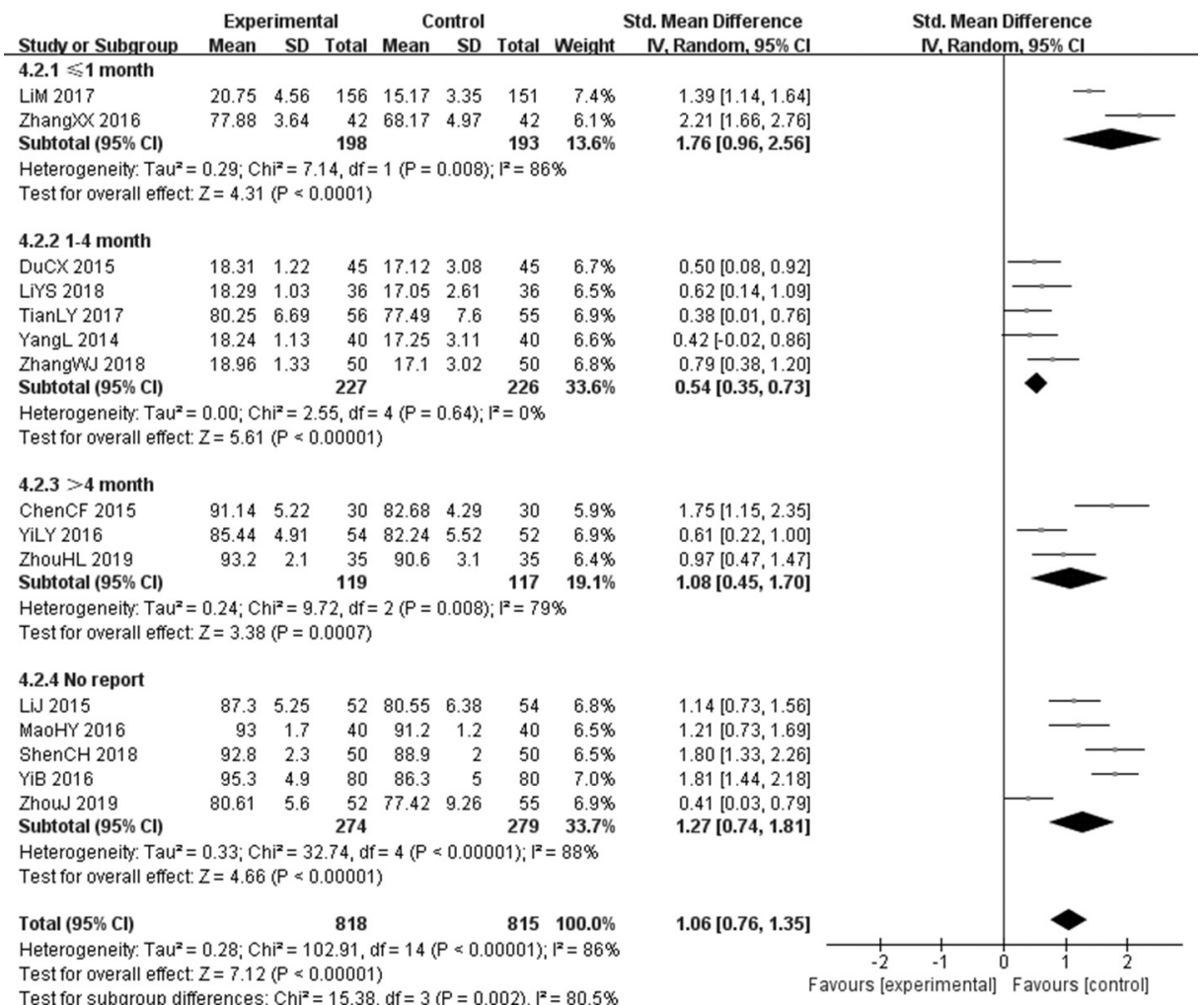

Figure 5. Subgroup analysis of the effect of intervention time on nursing students' operational achievement. 


\begin{tabular}{|c|c|c|c|c|c|c|}
\hline \multirow[t]{2}{*}{ Items } & \multicolumn{3}{|c|}{ Fixed-effect model } & \multicolumn{3}{|c|}{ Random-effect model } \\
\hline & SMD & $95 \% \mathrm{Cl}$ & $R^{2}(\%)$ & SMD & $95 \% \mathrm{Cl}$ & $P^{2}(\%)$ \\
\hline Skill score & 1.04 & $(0.94,1.15)$ & 86 & 1.06 & $(0.76,1.35)$ & 86 \\
\hline Learning interest & 0.92 & $(0.79,1.06)$ & 88 & 0.90 & $(0.50,1.30)$ & 88 \\
\hline Ability to judge and innovative thinking & 1.00 & $(0.76,1.24)$ & 92 & 1.22 & $(0.36,2.09)$ & 92 \\
\hline Abilities of understanding and perception & 0.58 & $(0.34,0.83)$ & 0 & 0.58 & $(0.34,0.83)$ & 0 \\
\hline Teaching satisfaction & 1.26 & $(1.12,1.39)$ & 88 & 1.29 & $(0.88,1.70)$ & 88 \\
\hline Ability to analyze and solve problems & 0.74 & $(0.55,0.93)$ & 88 & 0.85 & $(0.28,1.41)$ & 88 \\
\hline
\end{tabular}

Table 5. Sensitivity analysis.

Compared to traditional teaching, experiential teaching methods seem to improve the skills and abilities of nursing students in China. However, the problems of high heterogeneity, low methodological quality, and biased publications cannot be ignored. Future research requires rigorous inclusion of standards and rigorous quality assessment methods. In addition, a large sample and high-quality studies are needed in future to confirm its effectiveness.

\section{References}

1. AsadizakerM,AbedsaeediZ,AbediH,AlijanirenaniH, Moradi M, Jahan S. Improvement of the first training for baccalaureate nursing students - a mutual approach. Global J Health Sci. 2015;7:79-92.

2. Lee HY, Kim $\mathrm{Y}$, Kang $\mathrm{H}$, et al. An international comparison of Korean and Chinese nursing students with nursing curricula and educational outcomes. Nurse Educ Today. 2011;31:450-455.

3. Oyelana O, Martin D, Scanlan J, et al. Learnercentred teaching in a non-learner-centred world: an interpretive phenomenological study of the lived experience of clinical nursing faculty. Nurse Educ Today. 2018;67:118-123.

4. Li X, Mo L, Zhang P, Wang QY, Wang ZJ, Shi L. The application of different teaching methods in the clinical nursing skills training for nursing students: a network meta-analysis. Nurs J Chin People's Liberation Army. 2018;35:7-11 (in Chinese).

5. Kolb AY, Kolb DA. Learning styles and learning spaces: Enhancing experiential learning in higher education. Acad Manage Learn Educ. 2005;4:193-212.

6. Rodríguez-García M, Moya JLM, Pascual JLG, Cardenete-Reyes C. Experiential learning in practice: an ethnogrpahic study among nursing students and preceptors. Nurse Educ Pract. 2017; S1471595317307825.

7. West J, Stutzman SE, Atem F, Olson DM. Formatting an experiential learning education module to encourage dysphagia assessment

\section{Ethical approval}

Ethical issues are not involved in this paper.

\section{Conflicts of interest}

All contributing authors declare no conflicts of interest.

in apheresis patients. J Clin Apher. 2018; 33:72-77.

8. Kolb DA. Experiential Learning: Experience as the Source of Learning and Development. Englewood Cliffs, NJ: Prentice Hall; 1984.

9. Glover, TL, Horgas AL, Castleman J, et al. An experiential learning approach to primary palliative care nursing education: the comfort shawl project. J Hosp Palliat Nurs. 2017;19:534-538.

10. Liang $Y Y$, Jiang ZX, Zhang YC, BaiXL, Zeng H, ZhouJ. Application status and progress of experiential teaching in nursing teaching. $J$ Nurs Educ. 2011;26:880-882 (in Chinese).

11. Cooke PA, Tully MA, Cupples ME, et al. Randomised control trial of experiential learning to promote physical activity. Educ Primary Care. 2013;24:427-435.

12. Kolb D, Fry R. Toward an applied theory of experiential learning. In: Cooper C, ed. Theories of Group Process. London: Wiley; 1975:33-58.

13. Chen CF. The application of situational experience teaching method in clinical teaching of nursing students in emergency department. J Chin Med Manage. 2015;23:118-120 (in Chinese).

14. Du CX. Application of experiential teaching in clinical nursing teaching of Hematology Department. China Health Ind. 2015;12:130-132 (in Chinese).

15. Li J, Li F, Tan XJ, Yuan Q. Application of experiential teaching design in intravenous infusion skill 
operation teaching. Health Vocat Educ. 2015;33: 88-89 (in Chinese).

16. Li M. Applied research of experiential teaching method in the teaching of nursing safety and protection. Health Vocat Educ. 2017;35:114-115 (in Chinese).

17. Li YS, Zhang Y. Analysis of the effect of experiential teaching in clinical nursing teaching of Hematology Department. Health Vocat Educ. 2018;36:83-84 (in Chinese).

18. Mao HY, Ma B, Yu SX, Yang YL. Application of experiential teaching in nursing teaching. 2016;36:393 (in Chinese).

19. Shen $\mathrm{CH}$, Zhu LL. Application of experiential teaching in nursing teaching. J Chin Med Manage. 2018;26:27-28 (in Chinese).

20. Tian LY. Exploration of the application of experiential teaching method in medical nursing teaching. Res Curric Educ. 2017;52:106-107 (in Chinese).

21. Yi BDT. Observation on the effect of experiential teaching in nursing aesthetics teaching. Psychologist. 2016;22:210-211 (in Chinese).

22. Yi LY. Application effect of experiential teaching in practical teaching of nursing specialty in Higher Vocational Colleges. World Clin Med. 2016;10: 240-242 (in Chinese).

23. Yang L, Zhang JR. A comparative study of the application of experiential teaching and traditional teaching in clinical nursing teaching of urology surgery. Chin Med Guidel. 2014;12:398-399 (in Chinese).

24. Zhou HL. Application effect of experiential teaching in nursing teaching. Contemp Chin Med. 2019;26:191-193 (in Chinese).

25. Zhou J, Shi YH. Exploration on the application of experiential teaching method in surgical nursing teaching to improve the humanistic care ability of nursing students. Health Vocat Educ. 2019;37: 86-87 (in Chinese).
26. Zhang WJ. Application of experiential teaching in clinical nursing teaching of Hematology Department. Electron J Pract Clin Nurs. 2018;3:204-205 (in Chinese).

27. Zhang XX, Feng SY, Tan JL. The application of experiential teaching in training nursing students to place surgical positions. Qilu J Nurs. 2016;22: 120-121 (in Chinese).

28. Cara A, Robert DS, Norman HR, Lucinda H. Teaching an experiential mind-body method to medical students to increase interpersonal skills: a pilot study. Acad Psychiatry. 2015;39:316-319.

29. Hewson MG, Copeland HL, Mascha E, et al. Integrative medicine: implementation and evaluation of a professional development program using experiential learning and conceptual change teaching approaches. Patient Educ Couns. 2006;62:5-12.

30. Hurley TV. Experiential teaching increases medication calculation accuracy among baccalaureate nursing students. Nurs Educ Perspect. 2017;38:34.

31. Burnard P. Student nurses' perceptions of experiential learning. Nurse Educ Today. 1992;12:163-73.

32. Beard C, Wilson JP. Experiential Learning: A Handbook for Education, Training and Coaching. 3rd edn. London: Kogan Page; 2013.

33. Hill, B. Research into experiential learning in nurse education. Br J Nurs. 2017;26:932-938.

34. Cao XP, Ge W, Luo Y, Ye GY, Yao HM, Sun XJ. Research on the influence of participatory teaching method based on micro-film on the management ability of nursing students in Higher Vocational Colleges. Nurs Res. 2015;29:2463-2465 (in Chinese).

35. Hu JW, Liu ML, Guo Y. Micro-class combined with experiential teaching method in the teaching of peripheral venous indwelling needle operation for nursing students in cardiology department. Chin Med Bull. 2018;15:143-146,154 (in Chinese). 